\title{
A “NOVA POLÍTICA EXTERNA BRASILEIRA” DE TEMER PARA A AMÉRICA DO SUL
}

\section{Temer"s "new Brazilian foreign policy" towards South America}

\author{
Samir Perrone de Miranda ${ }^{1}$
}

\section{Introdução}

A "tradição" se mostra um elemento reiteradamente evocado (e reinventado) no discurso da diplomacia brasileira, constituindo expediente que supostamente contribui para a legitimação da orientação, dos princípios e dos valores perseguidos na atuação internacional do país. Nesta direção, a perenidade de determinada tradição incidiria sobre o horizonte de possibilidades e de escolhas políticas concretas do presente, atribuindo sentido de estabilidade, continuidade e previsibilidade a tais decisões (CERVO, 1994). Deste modo, não poderia deixar de representar um evento singular e disruptivo o anúncio, em maio de 2016, do lançamento de uma "nova política externa brasileira". Ainda mais se considerando o contexto de profunda cisão política que cercou sua emergência, mediante a implementação de um golpe parlamentar e jurídico travestido de processo de impeachment, o qual implicou no afastamento da presidente democraticamente eleita Dilma Vana Rousseff, sob a alegação de crime de responsabilidade (SOUZA, 2016; MATTOS; BESSONE; MAMIGONIAN, 2016).

O presente texto trata da política externa brasileira a partir da saída da presidente Dilma Rousseff, substituída por seu vice, Michel Temer (2016-2018). Mais especificamente, visa a analisar os efeitos desta gestão sobre as relações exteriores do Brasil com a América do Sul, partindo do pressuposto da vigência de um aviltamento político da integração regional (Cf. CASARÕES, 2016; PENNAFORTE, 2016) - uma pauta que se configurava prioritária para a diplomacia do país ao longo deste século XXI. O objetivo deste artigo consiste em examinar as diretrizes, os agentes e a suposta inovação desta política exterior que se implantou, considerando, particularmente, aspectos que demarcariam mudanças nos sentidos conferidos à integração regional. Para tanto, inicialmente são apresentadas iniciativas da política externa brasileira contemporânea que conformariam um relevante retrospecto no desenvolvimento da integração do entorno sul-americano.

\footnotetext{
${ }^{1}$ Professor do Programa de Pós-Graduação em Ciência Política e Relações Internacionais e do Departamento de Ciências Sociais da UFPB. Doutor em Ciência Política pela UFRGS. Mestre em Ciência Política pela UFRGS. Graduado em História pela UFRGS. Email: samirperrone@live.com
} 
Com base nisto, o artigo encaminha uma análise histórica e discursiva acerca desta autoproclamada "nova política externa brasileira”, com ênfase nos pronunciamentos do mandatário e dos chanceleres do país no período. Por fim, realiza-se uma avaliação das virtuais mudanças introduzidas pelo governo de Michel Temer no que tange ao papel atribuído à América do Sul e sua integração.

\section{A América do Sul na agenda da política externa brasileira}

Este artigo sumariza e prossegue pesquisas que vêm sendo desenvolvidas sobre o discurso da política externa brasileira para a integração sul-americana, contemplando a dinâmica de diferentes governos na Nova República (MIRANDA, 2014; MIRANDA \& RIBEIRO, 2015). Ao longo destas investigações, pode-se constatar que, desde a década de 1990, persiste uma relativa continuidade da pauta da integração sul-americana, constituída enquanto uma relevante diretriz da política externa brasileira contemporânea. Não obstante, verifica-se ainda a existência de modificações nas estratégias e nos sentidos articulados na construção discursiva de tal regionalização, denotando mudanças de ênfases no que se refere a conjunturas e governos.

De modo sumário, pode-se indicar uma importante anterioridade desta diretriz integracionista voltada para a esfera sul-americana. Com cuidado para não incorrer em uma leitura tautológica, poderia se indicar, ainda no final do último período ditatorial, o prenúncio de um movimento de progressivo acercamento regional, contemplando a diplomacia brasileira de aproximação à Argentina (VIZENTINI, 2004). A consolidação destas relações bilaterais viriam a ser o núcleo duro para a posterior construção de um nível de integração ampliado, incluindo, essencialmente, a chamada região do Cone Sul do continente, prevendo ainda a associação de outros países próximos. Assim, a criação do Mercado Comum do Sul (MERCOSUL), no governo de Fernando Collor de Mello (1990-1992), cristalizaria esta tendência. Não obstante, esta visão estratégica platina para a integração logo viria a ser modificada, a partir da chegada à presidência de Itamar Franco (1992-1994) e suas iniciativas para a configuração de uma área estratégica mais abrangente, calcada em uma noção sul-americana (MEDINA, 2001). Nesta conjuntura, o aspecto mais representativo desta opção de regionalização adotada seria a proposta brasileira para a criação da Área de Livre Comércio Sul-Americana (ALCSA).

Ao longo dos dois mandatos de Fernando Henrique Cardoso (1995-2002), as principais matrizes da política externa brasileira foram a defesa do multilateralismo e a busca pelo fortalecimento de relações na região sul-americana, principalmente em seu segundo governo (VIZENTINI, 2013). Apesar de o projeto da ALCSA não ter sido mobilizado de início, verifica-se uma retomada desta concepção de acercamento regional com a realização, por iniciativa brasileira, da I Reunião de Presidentes da América do Sul, no ano de 2000. Esta cúpula encaminhou uma proposta de união entre os países da região, com vistas a enfrentarem conjuntamente os dilemas do processo de globalização e melhor conseguirem negociar no plano internacional, tendo em conta, em particular, a então proposta estadunidense para a formação de uma Área de Livre Comércio das Américas (ALCA). 
A assunção do governo de Luiz Inácio Lula da Silva (2003-2010) guardou traços de continuidade com o último mandato de seu antecessor, mas redimensionou a projeção externa do país com o incremento da diplomacia presidencial. Este maior ativismo nas relações exteriores seria percebido, especialmente, no tocante à agenda da integração sul-americana (VIGEVANI \& CEPALUNI, 2011; VIZENTINI, 2013). Ao longo desta gestão, a atuação diplomática brasileira chegaria, inclusive, a assumir a pretensão por uma liderança regional, contrabalançada por um discurso que apelava para o princípio de uma solidariedade regional. Além disto, neste período, a lógica integracionista deixou de ser calcada no regionalismo aberto, com base no livre comércio e nos princípios neoliberais, passando a predominar o chamado regionalismo estrutural (LIMA \& COUTINHO, 2007). Em resumo, a integração sul-americana foi guindada ao status de grande prioridade da política externa brasileira, a qual se autoproclamaria como "ativa e altiva". Esta centralidade atribuída ao entorno do país viria a se consolidar nas propostas da Comunidade Sul-Americana de Nações (CASA) e, a seguir, na institucionalização da União de Nações Sul-Americanas (UNASUL) e na criação da Comunidade de Estados Latino Americanos e Caribenhos (CELAC).

Apesar de manter a América do Sul enquanto prioridade, a política externa na presidência de Dilma Vana Rousseff (2011-2016) sinalizaria algumas mudanças no modo de condução da diplomacia. A projeção brasileira para o acercamento regional passaria por uma retração relativa, condicionado por fatores externos, como a crescente presença chinesa no subcontinente (PEREIRA, 2012), mas principalmente em função de variáveis internas. O discurso desta administração enfatizaria a busca por maior pragmatismo e diversificação das relações exteriores, com o fito de perseguir parcerias estratégicas menos dispendiosas, bem como melhores oportunidades para o desenvolvimento do país. A política externa brasileira desta gestão se classificaria como "ativa e diversificada", em parcial remissão ao padrão diplomático de seu predecessor. Contudo, pode-se assinalar uma sensível redução nas viagens presidenciais aos países sulamericanos, assim como um perfil de baixo ativismo político e uma contenção do tema da suposta liderança brasileira sobre a região (CORNETET, 2014; MIRANDA \& RIBEIRO, 2015).

A partir deste breve retrospecto da integração da América do Sul na agenda da diplomacia brasileira contemporânea, cabe examinar os aspectos de eventuais continuidades e rupturas na dinâmica da "nova política externa brasileira”, decorrente do apeamento de Dilma Rousseff do poder. Para tanto, serão analisados discursos oficiais da presidência e do corpo diplomático do Brasil entre 2016 e 2018, particularmente pronunciamentos acerca da integração sul-americana, disponíveis em publicações oficiais do governo brasileiro. Ressalte-se que os discursos de política externa não devem ser concebidos enquanto mero "jogo de retórica", já que constituem aspecto fundamental para a compreensão de realidades, identidades e significados construídos por governos (HILL, 2003). Destarte, parte-se do entendimento que “estruturas no âmbito do discurso condicionam políticas possíveis” (WAEVER, 2005, p. 35). Nesta direção, convém atentar para o potencial analítico dos aspectos discursivos, apreendidos em sua historicidade e sua contingência, dada a permanente disputa entre discursos pela articulação de sentidos (Cf. LACLAU \& MOUFFE, 1985). 


\section{A “nova política externa brasileira”: o que há de novo?}

Em maio de 2016, como decorrência do afastamento da presidente eleita Dilma Rousseff durante o processo de impeachment, assume o poder interinamente o vice-presidente Michel Temer. Em seu discurso de posse, o peemedebista assinalou sua pretensão em implementar uma diplomacia embasada nos princípios consensuais previstos pela Constituição Federal de 1988, o que viria a permitir que a política externa "volte a representar os valores e interesses permanentes do nosso País" (TEMER, 2016, s/p.). Apesar da relativa vagueza que acompanhou este primeiro pronunciamento, o presidente interino já sinalizava um movimento de ruptura em relação à diplomacia desenvolvida por Rousseff, ressaltando a putativa necessidade de um retorno aos valores consolidados e à tradição de nossas relações exteriores.

Este cenário que se delineava apontava para a adoção prática de iniciativas previstas na cartilha "Uma ponte para o futuro", apresentada pelo PMDB cerca de seis meses antes. Neste documento, onde a agremiação manifestava publicamente sua contrariedade ao governo que ajudava a compor, registra-se a presença de algumas diretrizes para alavancar o desenvolvimento do Brasil, incluindo sugestões para a política externa. Nestes termos, a diplomacia brasileira deveria adequar-se à globalização, sem desperdiçar oportunidades "por razões políticas ou de alinhamento ideológico" (PMDB, 2015, p. 17). Mais especificamente, no que concerne ao âmbito de atuação regional, o mesmo documento antecipava as áreas consideradas fundamentais e recomendava o tipo de relacionamento com os países do entorno sulamericano:

[...] realizar a inserção plena da economia brasileira no comércio internacional, com maior abertura comercial e busca de acordos regionais de comércio em todas as áreas econômicas relevantes - Estados Unidos, União Europeia e Ásia - com ou sem a companhia do Mercosul, embora preferencialmente com eles. (PMDB, 2015, p. 18, grifo meu)

Imediatamente após a posse, e apesar de sua suposta provisionalidade enquanto mandatário, Temer implementa uma ampla reforma de gabinete, substituindo a maior parte dos ministros indicados por Rousseff, inclusive o diplomata de carreira Mauro Vieira, chanceler que ocupava o Ministério das Relações Exteriores. Em seu lugar, viria a assumir José Serra, senador pelo PSDB de São Paulo. De acordo com a análise de Miriam Saraiva e Paulo Afonso Velasco Júnior, uma sinalização do tipo de inovação que acompanhou esta gestão interina seria verificada a partir deste mesmo evento.

\footnotetext{
A indicação [de José Serra ao ministério] praticamente não tinha precedentes, nem tanto pelo fato de ser um político absolutamente estranho aos quadros diplomáticos profissionais, pois isso já tinha ocorrido em outros momentos, mas principalmente por ser um virtual candidato à Presidência da República nas eleições de 2018 e por enxergar o comando do Itamaraty como oportunidade para consolidar sua candidatura e elevar sua visibilidade. (SARAIVA \& VELASCO JÚNIOR, 2016, p. 312)
}

À observação dos autores sobre a ruptura que representou esta nomeação, soma-se ainda a constatação de as gestões petistas terem recebido reiteradas acusações de implementarem uma suposta ideologização e partidarização da política externa brasileira, críticas estas especialmente encaminhadas pelo próprio PSDB no âmbito da Comissão de Relações Exteriores e Defesa Nacional. Não obstante tais ilações, e 
conforme reiterado pela passagem supracitada, o Itamaraty encontrava-se há mais de vinte anos ${ }^{2}$ sob a chefia de diplomatas, o que valorizaria a independência, a qualificação e a tradição da Casa de Rio Branco. Assim, paradoxalmente, tal movimento de partidarização das relações exteriores parece advir mais propriamente da atuação destes críticos tucanos, em especial a partir da assunção de José Serra como chanceler. Neste sentido, a própria nomeação do senador peessedebista não poderia deixar de ser considerada como algo "novo" na política externa do país.

Cabe ressaltar que a autoatribuição do epíteto de "nova política externa brasileira" apareceria por ocasião do discurso de posse do ministro José Serra. Nesta oportunidade, o novo chanceler apresentou um conjunto de diretrizes que deveriam nortear sua gestão, dentre as quais se destaca a primeira delas:

\begin{abstract}
A diplomacia voltará a refletir de modo transparente e intransigente os legítimos valores da sociedade brasileira e os interesses de sua economia, a serviço do Brasil como um todo e não mais das conveniências e preferências ideológicas de um partido político e de seus aliados no exterior. A nossa política externa será regida pelos valores do Estado e da nação, não do governo e jamais de um partido. Essa nova política não romperá com as boas tradições do Itamaraty e da diplomacia brasileira, mas, ao contrário, as colocará em uso muito melhor. (SERRA, 2016, s/p.)
\end{abstract}

Novamente, causa estranheza esta remissão crítica a uma suposta ideologização e partidarização da política externa brasileira das gestões predecessoras, tendo em consideração a notória identificação partidária do sujeito emissor deste discurso. Convém aqui ressaltar que a predileção ideológica e a vinculação política não representam, a princípio, qualquer problema para o pleno exercício da diplomacia. Salienta-se apenas a nítida contradição que envolve este posicionamento assumido pelo chanceler brasileiro - a qual, aliás, viria a ser reiterada em outros comunicados. A preocupação com uma ruptura em relação ao legado da política externa anterior, assim como a priorização do "intercâmbio com parceiros tradicionais, com a Europa, os Estados Unidos e o Japão” (SERRA, 2016, s/p.) apenas denotam decisões eivadas de um viés ideológico, ainda que isto não seja assumido.

Em março de 2017, após pedir demissão por problemas de saúde, o ministro José Serra transmitiu o cargo a seu colega Aloysio Nunes Ferreira, também senador pelo PSDB de São Paulo e líder do governo Temer no Senado. O novo chanceler reiteraria a postura de crítica à suposta partidarização da política externa encaminhada no período petista, admoestando, também, a perseguição de valores considerados transcendentais da nação para o plano internacional.

\begin{abstract}
De que forma poderemos fazer da nossa política externa um instrumento para buscar novas oportunidades para o desenvolvimento material de nosso país? Trata-se de uma exigência de sempre, mas particularmente premente, para superarmos a atual crise que nos assola e que impõe mais do que nunca a distinção entre nossos interesses permanentes e os alinhamentos partidários e ideológicos contingentes. Reafirmo o que tem sido dito desde o início do governo Temer: a política externa tem que estar a serviço do País e não dos objetivos de um partido, qualquer que seja ele. (FERREIRA, 2017, s/p.)
\end{abstract}

A procura por uma obliteração do viés político-partidário da diplomacia brasileira, justamente em uma conjuntura capitaneada por dois políticos de carreira, não deixa de ser algo sintomático de uma posição

\footnotetext{
${ }^{2} \mathrm{O}$ último chanceler brasileiro com trajetória alheia à carreira diplomática e com vinculação política tradicional havia sido o peessedebista Fernando Henrique Cardoso, ministro do governo de Itamar Franco entre outubro de 1992 e maio de 1993.
} 
ideológica claramente assumida, embora sob o véu da negação. Assim, talvez o principal traço de distinção e “inovação" da política externa desta administração resida justamente na presença de agentes políticos tradicionais à frente do Itamaraty.

\section{O lugar da América do Sul: prioridade ainda?}

Área de projeção prioritária durante os governos de Lula da Silva, a América do Sul sofre um relativo declínio (CERVO \& LESSA, 2014) em seu desenvolvimento na agenda da política externa brasileira a partir da administração Rousseff. Contudo, o aviltamento das relações com a região sul-americana viria a se acentuar sobremaneira com a posse do presidente interino Michel Temer. A própria forma de emergência deste novo mandatário, em decorrência do afastamento de Dilma Rousseff do cargo, se transformaria em um relevante tópico de desgaste e fragilidade política para o desenvolvimento da diplomacia brasileira nesta conjuntura, particularmente no plano regional. As severas críticas do secretário-geral da UNASUL, Ernesto Samper, colocando em suspeição o processo de impeachment então em curso no Brasil e, ainda, ventilando a adoção de sanções ao país a partir da evocação da cláusula democrática do bloco (GAZZOLA, 2018), constituíram uma situação "nova" e constrangedora à tradição da política externa brasileira.

Nesta direção, mostra-se evento sintomático de tal dissenso regional o não reconhecimento institucional da UNASUL a este novo governo brasileiro. Na página eletrônica do bloco, o espaço reservado para o registro do nome e da fotografia do mandatário do Brasil encontrou-se, durante a gestão de Michel Temer, preenchido apenas com o nome do país e uma imagem da bandeira nacional, uma situação sui generis que contrasta com a veiculação da nominata completa e dos retratos de todos os chefes de Estado da América do Sul. As opções políticas da gestão Temer e este tensionamento das relações com a UNASUL ajudam a explicar o relativo abandono da prioridade atribuída à região ao longo desta quadra. A partir destas interdições, a ênfase comercial no MERCOSUL e nas negociações bilaterais com os países do entorno mostrou-se um caminho mais viável para esta administração.

Em seu discurso inaugural na função, o ministro José Serra descreveria justamente as relações com a Argentina e com o MERCOSUL como uma das dez diretrizes que embasariam a diplomacia do Brasil.

\footnotetext{
Um dos principais focos de nossa ação diplomática em curto prazo será a parceria com a Argentina, com a qual passamos a compartilhar referências semelhantes para a reorganização da política e da economia. Junto com os demais parceiros, precisamos renovar o Mercosul, para corrigir o que precisa ser corrigido, com o objetivo de fortalecê-lo, antes de mais nada quanto ao próprio livre-comércio entre seus países membros, que ainda deixa a desejar, de promover uma prosperidade compartilhada e continuar a construir pontes, em vez de aprofundar diferenças, em relação à Aliança para o Pacifico, que envolve três países sul-americanos, Chile, Peru e Colômbia, mais o México. Como disse Enrique Iglesias, muito bem observado, não podemos assistir impassíveis à renovação de uma espécie de Tratado de Tordesilhas, que aprofundaria a separação entre o leste e o oeste do continente sulamericano. (SERRA, 2016, s/p.)
}

O discurso do chanceler assinala a importância estratégica da Argentina e do MERCOSUL, mas introduz ressalvas sobre a dinâmica destas relações e, ademais, enfatiza seu aspecto comercial. Estas indicações podem ser interpretadas como parte de uma busca por maior pragmatismo diplomático, uma tendência que remontaria, inclusive, à gestão de Dilma Rousseff. De todo modo, esta diretriz reputa como 
necessária uma retificação das normas que regem o MERCOSUL e também recomenda a aproximação deste bloco à iniciativa da Aliança do Pacífico. A despeito dos eventuais ganhos mercantis, uma cooperação entre estes dois grupos de países sul-americanos representaria um rebaixamento da pauta integracionista, reduzindo suas relações ao aspecto meramente livre-cambista, em um retorno ao modelo de regionalismo aberto da década de 1990. Além disto, cabe ponderar que se o diálogo que política externa brasileira do período petista manteve com a Aliança Bolivariana para os Povos da Nossa América (ALBA) poderia ser taxado como algo "ideológico" ou "partidário", a atual opção diplomática pela Aliança do Pacífico, com o notório alinhamento político de seus países membros aos preceitos estadunidenses, viria a constituir uma situação análoga.

A chegada de Aloysio Nunes ao comando do Itamaraty não trouxe alteração quanto a este entendimento de José Serra sobre o papel da América do Sul para a política externa brasileira. Em seu discurso de posse, o novo ministro, inclusive, seria evasivo quanto à própria delimitação de um espaço regional estratégico para o país: "Continuaremos a dar a necessária prioridade ao nosso relacionamento com as nações da América do Sul, da América Central, do conjunto da América Latina e do Caribe” (FERREIRA, 2017, s/p.). Ademais, tal como seu predecessor, o chanceler Aloysio Nunes indicaria a pretensão em dar prosseguimento a uma crescente aproximação entre MERCOSUL e Aliança do Pacífico.

Além dos discursos dos ministros, o relatório intitulado "Brasil: um país em busca de uma grande estratégia”, publicado pela Secretaria Especial de Assuntos Estratégicos em maio de 2017, oferece subsídios para a compreensão dos sentidos da integração sob a gestão Temer. Este documento instava o governo a adotar um planejamento estratégico e a perseguir o que reputava como "interesses nacionais" de longo prazo, com vistas a superar supostas contradições na atuação da política externa brasileira recente, destacando seu entendimento da integração sul-americana enquanto um fracasso. Ainda segundo o relatório em questão, nossa política exterior deveria ser pensada e avaliada em termos de resultado econômico imediato, comparando, por exemplo, o investimento dispensado para a abertura de embaixadas brasileiras e seu retorno em termos de fluxo comercial e financeiro com os respectivos países. Especificamente quanto ao papel da América do Sul, esta publicação da Secretaria Especial de Assuntos Estratégicos denota a ênfase no sentido mercantil a guiar a integração, ignorando ou reduzindo a importância dos demais aspectos que envolvem a regionalização.

\footnotetext{
O Brasil, em suma, permaneceu atrelado ao Mercosul e a seus sócios, economias no mais das vezes instáveis e problemáticas. Continuou desprovido de estratégia viável de negociações comerciais, carente de maior competitividade industrial e incapaz de reagir política e diplomaticamente às transformações ocorridas no sistema de governança comercial global. Com tudo isso, o Brasil isolou-se comercialmente, perdendo oportunidades, influência e investimentos. (BRASIL, 2017, p. 24)
}

A alternativa cogitada seria rever ou retomar a estratégia nacional, onde, em termos comerciais, o Brasil deveria envidar esforços para uma maior aproximação a centros econômicos considerados mais dinâmicos. Nesta leitura, a opção pela Aliança do Pacífico mostrar-se-ia mais atrativa que a manutenção das relações constituídas no âmbito do MERCOSUL ou da UNASUL, esferas estas que, na ótica do governo Temer, não gerariam os dividendos esperados nos marcos de uma "grande estratégia" para o país. 
Além deste aviltamento da América do Sul, resumindo a dinâmica da integração regional ao livrecomércio, cabe ressaltar outra inovação da política externa brasileira deste período, conforme sumarizado em discurso do chanceler Aloysio Nunes Ferreira:

\begin{abstract}
Todos nós sabemos que não pode haver democracia sem liberdade de imprensa, sem liberdade de organização. Não há democracia sem um judiciário independente, capaz de dar remédio às arbitrariedades do poder contra os cidadãos. Não há democracia sem regras claras que permitam a participação dos cidadãos organizados em partidos políticos nas deliberações que dizem respeito aos rumos de seu país. Como tampouco há democracia enquanto cidadãos que exerçam pacificamente seu direito de oposição estejam encarcerados. (FERREIRA, 2018, s/p.)
\end{abstract}

Ainda que pareça referir-se ao momento político e institucional do Brasil, o ministro manifestava, perante a Assembleia Geral da Organização dos Estados Americanos (OEA), a preocupação do governo Temer para com os rumos do regime democrático venezuelano. A sequência desta sua intervenção complementaria e esclareceria os alocutários sobre esta interpretação de então da política externa brasileira:

\footnotetext{
A pergunta que se faz, e sobre a qual eu tenho um ponto de vista, é se os traços essenciais da democracia, meu prezado chanceler, estão presentes na Venezuela hoje. Vou lhe dizer com toda lealdade e franqueza. O senhor conhece a nossa opinião. A nossa representação entende que não. (FERREIRA, 2018, s/p.)
}

Estas manifestações de crítica à situação interna da Venezuela passaram a ser recorrentes da parte dos representantes das relações exteriores do Brasil. Além de claramente destoar da tradicional ponderação diplomática do país, o posicionamento cristalizado pelos chanceleres tucanos do período passou a isolar e denunciar internacionalmente um dos principais parceiros regionais do Brasil. A renitente crítica brasileira ao regime político venezuelano acabaria por soar como algo excessivo, como a insinuação de uma tentativa de intervencionismo ou interferência em um país soberano - ou poderia então soar como um chiste, tendo em vista a fragilidade do governo Temer em termos de sua própria legitimidade.

Nesta linha, cabe referir a ocasião em que o chanceler brasileiro foi acusado pela representação uruguaia de uma tentativa de suborno para impedir a Venezuela de assumir a presidência rotativa do MERCOSUL (PENNAFORTE, 2016, p. 11). Todavia, mesmo tendo assumido a liderança do bloco em 2016, a Venezuela passaria a sofrer com o boicote do Brasil aos trabalhos. Esta situação atingiria seu paroxismo em agosto de 2017, a partir de uma reunião extraordinária do MERCOSUL, convocada por iniciativa brasileira, quando os países membros invocaram o Protocolo de Ushuaia - a cláusula democrática do bloco - e aprovaram a suspensão da Venezuela. Ao fim e ao cabo, o isolamento de nações vizinhas e o esvaziamento de iniciativas para a integração regional parecem ser os principais resultados desta "nova política externa brasileira".

\title{
Considerações finais
}

Ao longo deste artigo, buscou-se examinar a "nova política externa brasileira" anunciada pela administração de Michel Temer, ponderando os eventuais traços de inovação, particularmente em seu 
discurso quanto ao relacionamento com a região sul-americana. Neste sentido, pode-se observar a preocupação desta gestão em romper com as diretrizes e o padrão de projeção exterior que teriam caracterizado os governos do PT, reputados como "ideológicos" e "partidários" no plano internacional. Os pronunciamentos analisados denotam que a diplomacia da administração Temer, implementada sob o comando de agentes políticos peessedebistas, acabou por desenvolver-se, paradoxalmente, sob estas características outrora censuradas. Neste sentido, a dinâmica encaminhada no período quebraria a tradição de centralidade da burocracia do Itamaraty na condução das relações exteriores, algo que se percebe, por exemplo, na significativa elevação de "tom" que passou a grassar nos discursos brasileiros.

Quanto ao lugar da América do Sul nesta "nova política externa”, chama a atenção o rebaixamento de sua importância na agenda e na constituição do discurso da diplomacia brasileira. Antes considerado como grande prioridade, este subcontinente passou a representar um espaço de menor relevância, quando não um front de desgastes para nossas relações exteriores. Neste período, verifica-se uma redução do número de viagens, participações em eventos e pronunciamentos no plano regional durante o governo de Michel Temer, algo um tanto sintomático da deterioração das principais instituições sul-americanas, como o MERCOSUL e, em especial, a UNASUL. Por contraste, a diplomacia brasileira priorizou uma aproximação à Aliança do Pacífico, rebaixando o sentido da integração regional aos aspectos econômicos e livre-cambistas. Ademais, a política exterior de Temer "inovou" ao desenvolver uma dinâmica conflituosa e persecutória em relação à Venezuela, um importante parceiro do país na América do Sul, gestando algo que, inclusive, poderia ser interpretado como ameaça a nossos tradicionais princípios diplomáticos de não-intervenção e defesa da soberania.

Em termos comparativos, dificilmente se poderia classificar a política externa da administração Temer como "ativa” ou "altiva”; ademais, não configuraria uma mera continuidade do putativo "declínio" (CERVO \& LESSA, 2014) principiado no governo de Dilma Rousseff. Talvez a atual quadra histórica de nossa diplomacia, particularmente para a região sul-americana, possa ser descrita propriamente como uma “inserção subordinada” (MALDONADO \& ARRUDA, 2016), uma busca de "autonomia pela inércia" (VELASCO JÚNIOR, 2017), ou uma "retração política” (NUNES \& RODRIGUEZ, 2017). Ou talvez, poderíamos aqui sugerir, simplesmente descrever este período e sua pauta integracionista como um "retrocesso", ainda que travestido como algo supostamente "novo".

Cabe ainda aludir ao potencial efeito negativo da gestão Temer contar com seus dois chanceleres investigados por crimes de corrupção - algo que, infortunadamente, também constituiu uma situação "nova” no histórico da política externa brasileira. A despeito da comprovação ou não das acusações contra os dois ministros, tal circunstância, indubitavelmente, arranharia a imagem e a tradição do Itamaraty. Por fim, pode-se indicar que o resultado das eleições de 2018 sinalizou que o porvir também não se mostra muito auspicioso para nossas relações exteriores, particularmente quanto ao papel atribuído à América do Sul - como, aliás, dentre outras tantas áreas do governo a serem afetadas pelo ascenso reacionário no Brasil. 


\section{REFERÊNCIAS}

BRASIL. Relatório de Conjuntura $\mathbf{n}^{\circ}$ 01: Brasil: um país em busca de uma grande estratégia. Brasília: Secretaria de Assuntos Estratégicos, 2017.

CASARÕES, Guilherme Stolle Paixão e. A política externa interina e os riscos à integração regional. Conjuntura austral, v. 7, n. 37, p. 81-93, 2016.

CERVO, Amado Luiz. O desafio internacional. Brasília: Ed. da UnB, 1994.

CERVO, Amado Luiz; LESSA, Antônio Carlos. "O declínio: inserção internacional do Brasil (2011-2014)". Revista Brasileira de Política Internacional, v. 57, n. 2, p. 133-151, 2014.

CORNETET, João Marcelo Conte. “A política externa de Dilma Rousseff: contenção na continuidade”. Conjuntura Austral, v. 5, n. 24, p. 111-150, 2014.

FERREIRA, Aloysio Nunes. "Texto-base para o discurso de posse do Ministro de Estado das Relações Exteriores, Aloysio Nunes Ferreira, em Brasília, 07 de março de 2017”. MRE. Brasília: MRE, 2017. Disponível em: <http://www.itamaraty.gov.br>. Acesso em: 19 ago. 2018.

FERREIRA, Aloysio Nunes. "Discurso proferido pelo Ministro das Relações Exteriores, Aloysio Nunes Ferreira, por ocasião $48^{\circ}$ período ordinário de sessões da Assembleia Geral da OEA, Washington, 04 de junho de 2018”. MRE. Brasília: MRE, 2018. Disponível em: <http://www.itamaraty.gov.br>. Acesso em: 22 set. 2018.

GAZZOLA, Ana Elisa Thomazella. "A política externa de Temer sob as reflexões atuais acerca do regionalismo sul-americano”. Observatório de Regionalismo. São Paulo: Unesp, 2018.

HANSEN, Lene. Security as practice: discourse analysis and the Bosnian War. London: Routledge, 2006.

HILL, Christopher. The changing politics of foreign policy. New York: Palgrave Macmillan, 2003.

LACLAU, Ernesto; MOUFFE, Chantal. Hegemony and socialist strategy: towards a radical democratic politics. London: Versus, 1985.

LIMA, Maria Regina Soares de; COUTINHO, Marcelo Vasconcelos. "Uma versão estrutural do regionalismo". In: DINIZ, Eli (Org.). Globalização, Estado e desenvolvimento: dilemas do Brasil no novo milênio. Rio de Janeiro: FGV, 2007.

MALAMUD, Andrés. “La política externa de Dilma Rousseff: ¿menos de lo mismo?”. Iberoamericana, v. XI, n. 41, p. 174-179, 2011.

MALDONADO, Fabio de Oliveira; ARRUDA, Pedro Fassoni. "La política externa del gobierno Temer y América Latina”. Revista Política Latino Americana, n. 3, p. 01-17, 2016.

MATTOS, Hebe; BESSONE, Tânia; MAMIGONIAN, Beatriz G. (Org.). Historiadores pela democracia: o golpe de 2016 e a força do passado. São Paulo: Alameda, 2016.

MEDINA, Guillermo. “América Latina, estrategias en conflito”. Política Exterior, n. 79, p. 155-173, 2001.

MIRANDA, Samir Perrone de. A integração da América do Sul no discurso da política externa brasileira (1992-2010). Tese (Doutorado em Ciência Política) - Universidade Federal do Rio Grande do Sul, Porto Alegre, 2014.

MIRANDA, Samir Perrone de; RIBEIRO, Camille Amorim Leite. A América do Sul na política externa de Dilma Rousseff: continuidades e rupturas. Anais do $1^{\circ}$ Seminário Internacional de Ciência Política. Porto Alegre, 2015. Disponível em: <https://www.ufrgs.br/sicp/wp- 
content/uploads/2015/09/PERRONE-MIRANDA-2015-A

América-do-Sul-na-pol\%C3\%ADticaexterna-de-Dilma-Rousseff.pdf >. Acesso em 03 ago. 2018.

NUNES, Raul Cavedon; RODRIGUEZ, Vitória Gozalez. “A política externa brasileira de Temer-Serra: retração política e subordinação econômica”. Boletim de Conjuntura - NERINT, v. 1, n. 4, p. 3039, 2017.

PENNAFORTE, Charles. “A política externa em novos tempos: o fim da perspectiva ativa e altiva?”. In: Anales del VIII Congreso de Relaciones Internacionales. La Plata, 2016. Disponível em: <http://congresos.unlp.edu.ar/index.php/CRRII/CRRII-VIII/paper/viewFile/3427/848>. Acesso em 04 set. 2018.

PEREIRA, Lia Valls. "O efeito China nas exportações brasileiras na América do Sul”. Conjuntura Econômica, v. 66, n. 10, p. 44-48, 2012.

PMDB. Uma ponte para o futuro. Brasília: Fundação Ulysses Guimarães, 2015. Disponível em:<https://www.fundacaoulysses.org.br/wp-content/uploads/2016/11/UMA-PONTE-PARA-OFUTURO.pdf $>$. Acesso em 15 ago. 2018.

SARAIVA, Miriam Gomes. “Balanço da política externa de Dilma Rousseff: perspectivas futuras?”. Relações Internacionais, n. 44, p. 25-35, 2014.

SARAIVA, Miriam Gomes; VELASCO JÚNIOR, Paulo Afonso. “A política externa brasileira e o 'fim de ciclo' na América do Sul: para onde vamos?”. Pensamiento propio, v. 21, n. 44, 2016.

SERRA, José. "Discurso do Ministro José Serra por ocasião da cerimônia de transmissão do cargo de Ministro de Estado das Relações Exteriores, em Brasília, 18 de maio de 2016”. MRE. Brasília: MRE, 2016. Disponível em: <http://www.itamaraty.gov.br>. Acesso em: 15 mar. 2018.

SOUZA, Jessé. A radiografia do golpe: entenda como e por que você foi enganado. Rio de Janeiro: LeYa, 2016.

TEMER, Michel. "Discurso do Presidente da República, Michel Temer, durante cerimônia de posse dos novos ministros de Estado, em Brasília, 12 de maio de 2016". Presidência da República. Brasília: Planalto, 2016. Disponível em: <http://www2.planalto.gov.br/ acompanheplanalto/discursos/discursos-do-presidente-da-republica/discurso-do-presidente-da-republicamichel-temer-durante-cerimonia-de-posse-dos-novos-ministros-de-estado-palacio-do-planalto>. Acesso em: 10 mar. 2018.

VELASCO JÚNIOR, Paulo Afonso. "A política externa do governo Temer: continuidade, inércia e a falta de uma estratégia de inserção internacional”. In: Anales del IX Congreso Latino Americano de Ciencia Política. $2017 . \quad$ Dontevideo, em: <http://www.congresoalacip2017.org/site/anaiscomplementares2\#P>. Acesso em: 15 dez. 2017.

VIGEVANI, Tullo; CEPALUNI, Gabriel. A política externa brasileira: a busca da autonomia, de Sarney a Lula. São Paulo: Ed. da Unesp, 2011.

VIZENTINI, Paulo Fagundes. A política externa do regime militar brasileiro: multilateralização, desenvolvimento e construção de uma potência média (1964- 1985). 2. ed. Porto Alegre: Ed. da UFRGS, 2004.

VIZENTINI, Paulo Fagundes. A projeção internacional do Brasil: 1930-2012. Rio de Janeiro: Elsevier, 2013.

WAEVER, Ole. "European integration and security: analyzing French and German discourse on State, Nation, and Europe". In: HOWARTH, David; TORFING, Jacob (Eds.). Discourse theory in European politics: identity, policy and governance. London: Palgrave Macmillan, 2005. 
Recebido em 8 de agosto de 2019. Aprovado em 29 de agosto 2019. 


\title{
RESUMO
}

O artigo busca abordar a autoproclamada "nova política externa brasileira" da gestão Michel Temer e seus efeitos sobre as relações com a América do Sul. Considerando o retrospecto de iniciativas do Brasil para o acercamento regional, desenvolve-se uma análise histórica e discursiva desta diplomacia, assinalando suas diretrizes, seus agentes, bem como eventuais mudança nos sentidos atribuídos à integração sul-americana pauta prioritária para relações exteriores do país no século XXI.

Palavras-chave: Política Externa Brasileira; América do Sul; Michel Temer.

\begin{abstract}
The article seeks to approach Michel Temer's self-proclaimed "new Brazilian foreign policy", and its effects over the relations with South America. Considering a review of Brazil's initiatives for the regional approach, a historical and discursive analysis of this diplomacy is developed, indicating its guidelines, its agents, as well as possible changes in the meanings attributed to South American integration - a priority agenda for Brazilian foreign relations in the 21 st century.
\end{abstract}

Key-words: Brazilian Foreign Policy; South America; Michel Temer.

\section{COPYRIGHT:}

Este é um artigo publicado em acesso aberto e distribuído sob os termos da Licença de Atribuição Creative Commons, que permite uso irrestrito, distribuição e reprodução em qualquer meio, desde que o autor e a fonte originais sejam creditados.

This is an open-access article distributed under the terms of a Creative Commons Attribution License, which permits unrestricted use, distribution, and reproduction in any medium, provided that the original author and source are credited.

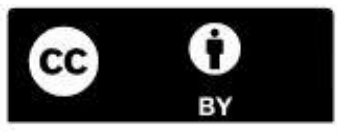

